\title{
Phytoprotection
}

\section{Research Challenges and Needs for Safe Utilization of Transgenic Viruses}

\section{Ivan E. Gard}

Volume 79, numéro 4, 1998

OECD Workshop - Sustainable Pest Management, Safe Utilization of New Organisms in Biological Control. Montréal, Québec, Canada. September 27-30, 1998.

Atelier de l'OCDE - Gestion durable des ennemis des cultures, Utilisation sécuritaire de nouveaux organismes de lutte biologique. Montréal, Québec, Canada. 27-30 Septembre 1998.

URI : https://id.erudit.org/iderudit/706171ar

DOI : https://doi.org/10.7202/706171ar

Aller au sommaire du numéro

Éditeur(s)

Société de protection des plantes du Québec (SPPQ)l

ISSN

0031-9511 (imprimé)

1710-1603 (numérique)

Découvrir la revue

Citer cet article

Gard, I. E. (1998). Research Challenges and Needs for Safe Utilization of Transgenic Viruses. Phytoprotection, 79(4), 131-135.

https://doi.org/10.7202/706171ar d'utilisation que vous pouvez consulter en ligne. 


\title{
Research Challenges \& Needs for Safe Utilization of Transgenic Viruses
}

\author{
Ivan E. Gard, Ph.D. \\ American Cyanamid Company, P.O. Box 400, Princeton, New Jersey 08543-0400 USA
}

\section{INTRODUCTION}

The commercialization of baculoviruses has had a long, variable history. Entomologists early on recognized that these viruses could be utilized as insect-specific control tools and numerous attempts were made to develop the wild-type viruses as commercial insecticides. Some of the earlier products were Elcar TM, Gypcheck TM, Neocheck-S ${ }^{\mathrm{TM}}$, and more recently, products from ThermoTrilogy, GemStar ${ }^{\mathrm{TM}}$ and Spod- $X^{\mathrm{TM}}$. These latter products are presently being commercially produced and marketed in various locations around the world. While the wildtype baculoviruses have realized a small level of success, the real commercial potential lies in an insect-specific insecticide that will effectively control an insect population equal to, or close to, the same efficiency as commercial insecticides. The advent of understanding the genetic code and the manipulation of it have introduced a whole new era for exploration and development (i.e., the production of transgenic insect viruses for insect control). The use of these tools to insert toxin genes which, when expressed, can speed the killing effect of a baculovirus, is the subject of research ongoing in two major corporations, DuPont and American Cyanamid. Through the insertion and expression of heterologous genes in a baculovirus vector, the long-term problem of slow kill of a baculovirus is overcome. This is achieved by altering the mode-of-action of the baculovirus [i.e., the virus kills the insect via the expression of a protein (chemical) vs. consuming virtually every cell in the insect body to affect reproduction of the virus itself]. Since the recombinant baculovirus is a changed from the wildtype, one must assess the recombinant for new properties for a potentially different environmental impact as compared to its wild-type parent. This is one of the issues we are all here to discuss (i.e., what are the research challenges that face us in the safe utilization of these new transgenic insecticide tools?).

Let's look at the various safety aspects surrounding each of the two components of this new system that have been brought together: (1) the baculovirus, and (2) the toxin gene.

\section{BACULOVIRUS SAFETY}

There has been a long, close evolutionary relationship between baculoviruses and arthropods. This has led to very specific evolutionary adaptations due to this close relationship. Probably the best illustration of this co-evolution is represented by the occlusion body, a proteinacious crystal that dissolves only at a high $\mathrm{pH}$ and is extremely sensitive to the high $\mathrm{pH}$ found in the target insect midgut. This occlusion body allows the occluded virions to survive in the environment but, upon consumption by a target host, is readily dissolved and able to quickly infect the midgut cells of the insect. The infection expands from that point throughout the whole insect body. Conversely, the vertebrate digestive tract, is usually neutral or acidic. The 
occlusion body will either pass through the vertebrate digestive tract or become inactivated during the digestion process.

The safety of baculoviruses has been widely evaluated over the last 30 years. Several summaries are available (Doller, 1985; Burges et al., 1980, Ignoffo, $1973,1975)$. Safety studies with baculoviruses have been conducted on mice, guinea pigs, rats, monkeys, and even humans. All data indicate that baculoviruses are safe. In the human study, Helicoverpa zea NPV polyhedra were ingested by 10 individuals at a dose of ca. 6 billion polyhedra over a 5-day period (Heimpel and Buchanan, 1967) which caused no ill effects. In a longerterm study, 6 persons were exposed to NPV during 26 months of commercial production, and showed no adverse effects of this long-term exposure (Huang et al., 1977). Analysis and bioassay of blood samples did not find any baculoviral antigens, antibodies, or any infectious baculovirus in blood samples.

One interesting factor is the environmental load of NPVs that humans are exposed to on a regular basis. Heimpel et al. (1973) showed that polyhedron counts on cabbage taken from supermarket shelves contained between 2 and 100 million polyhedra per square inch. Heimpel estimated, using these numbers, that a typical cole slaw serving might contain as many as $1 \times 10^{8}$ polyhedra. So, as you can see, we are constantly exposed to these viruses.

Baculoviruses have also demonstrated safety even within the invertebrates. Baculoviruses, for the most part, have very limited host-ranges, mostly infecting the order Lepidoptera, and in general, infecting only a few species in any genus.

\section{TOXIN SAFETY}

Commercial companies have chosen insect-specific toxins, whose respective genes are utilized, to incorporate in the baculovirus genome. This essentially gives a double layer of safety to the viral construct (i.e., the virus is the first limiting factor with its insect specificity, and the toxin gene is limiting also because of its insect specificity). American Cyanamid and DuPont have both chosen initially two scorpion toxin genes, AalT, from the scorpion, Androctonus australis, and the LqIT gene from the scorpion, Leiurus quinquestritus hebrus, respectively. Significant research has been conducted on both toxins. Zlotkin et al. $(1991,1993)$ and Moskowitz et al. (1994) demonstrated that both toxins are insect-specific.

\section{ECOLOGICAL ISSUES}

It is well-known in the literature that occlusion bodies of baculoviruses can persist for many years in soil. The addition of an insect-specific toxin gene does not affect this physical characteristic of the virus, therefore, one would anticipate that its persistence in the environment would parallel that of its wild-type parent. Perhaps a more important issue is whether the recombinant virus could become established in the environment, increase in number, and initiate epizootics unrelated to its original intent of introduction as a biopesticide to control or suppress a pest insect. When one considers basic biological principles and the available data, the suggestion is that it is very unlikely that the recombinant could supplant its wild-type parent and unbalance the scales of nature.

The main goal of genetic engineering of a baculovirus is to increase the speed-of-kill of the target pest. As previously mentioned, the kill time for a wild-type virus varies from 5 - 15 days, with the genetically engineered virus, this can be reduced to 2 - 3 days obviously a major benefit in protecting a crop. Theoretically, if this result is achieved, the virus would go through a reduced number of reproductive cycles, thus reducing the amount of virus produced, compared to the wild-type parental strain. Experimental results with the baculovirus containing the AalT toxin indicate that the recombinant produces $75-93 \%$ fewer polyhedra, compared to the wild-type parent (American Cyanamid, 1994). Competition 
studies (wild-type vs. recombinant baculovirus) indicate that the wild-type was able to out-compete and overcome the phenotypic expression of the constrictive paralysis demonstrated by a baculovirus containing the AalT gene. In one such study conducted at American Cyanamid, a 1:10 mixture of the wildtype to AalT-expressing recombinant, was fed to larvae of the permissive insect, Heliothis virescens. After 6 days, all of the larvae in each dose were harvested and processed to extract the polyhedra. Each mixture was then fed to a second generation of larvae. This process was continued for 6 generations. Two methods were used to track the amount of AalT-expressing virus, the contractile phenotype, and molecular analysis of the viral genomes in the final polyhedra extractions. The results demonstrated a rapid decrease in the AalT-expressing virus and a rapid increase in the wild-type parent. In 6 generations, the AalT phenotype and genotype were lost. Very clearly, the recombinant is less fit to survive in the environment, and would have considerably less environmental impact than its wild-type parent. The data indicate that the recombinant would be unable to displace the parental strain.

Wood (1991) indicated that one area for concern is genetic transfer or genetic reassortment (i.e., could the release of a recombinant baculovirus enable that recombinant to transfer its heterologous gene into other related or unrelated viruses, thus introducing potential consequences of unknown result?). Two issues must be considered when evaluating the potential of an inserted gene from a recombinant baculovirus jumping to another organism: (1) what is the likelihood of a genetic exchange occurring between the recombinant baculovirus and another organism? and (2) what would the consequences of such an event be?

It is an established fact that genetic exchange can and does occur in nature. However, the integrity of a species is protected by significant barriers to gene movement, which can limit or reduce the likelihood of genetic exchange. Several barriers to exchange exist. The first barrier to genetic exchange, is that both the donor and recipient organism must be replicating at the same time in the same cell of an infected insect. These time and space requirements pose limits on the likelihood of exchange. The fact that these baculoviruses reproduce in the nucleus, requires that they not only be in the same cell, but that they also be in the same cell compartment (the nucleus).

Another important barrier to genetic exchange is the relationship of genetic material of the donor and of the recipient. Even if the two viruses infect the same host cell at the same time in the same cellular compartment, differences in replication and composition of viral genome can serve to limit exchange of genetic information. These factors realistically limit situations, where an exchange of genetic information could occur, to two highly related baculoviruses.

The consequences of any genetic exchange, assuming they occur, would be extremely limited. New genetic traits will become "fixed" in a population only if they confer a selective advantage to the species. As indicated earlier, the heterologous toxin gene significantly reduces the fitness of the recombinant virus to persist in the environment. It would follow that any new virus acquiring a toxin gene would also be environmentally less fit.

\section{BENEFITS}

Biotechnology obviously will have significant economic and societal benefits to agriculture in the future. We are beginning to reap some of these benefits through herbicide-tolerant and $B t$ producing crops. The commercial availability of transgenic insect viruses for use as insecticides is certain within the next 2 - 3 years. This first generation of transgenic baculoviruses, as I have previously discussed, passed the basic parameters for environmental and toxicological safety. However, there is one issue which is the most important and thus saved for the final discussion, that being the problem of societal issues. 
Biotechnology has come under general public scrutiny and certain environmental activist groups have attacked biotechnology from scientific, ethical, and personal viewpoints. Meeting the challenge of these societal issues is going to be the greater challenge in the introduction of biotechnology, whether it's genetically manipulated plants or microorganisms. The major question is "How do we overcome ignorance, fear, and ethical concerns as they relate to their negative impact on the use of biotechnology in general, and more directly, transgenic baculoviruses?".

In the past, we (as credible scientists) have been able to tell the public that all is okay, and they have accepted it. However, the credibility of the scientific community has been eroded through certain negative experiences, especially in the areas of nuclear physics and chemistry. Principles were described by Brown (1987) which show the essentials of dealing with the public sector. These have great applicability to communicating the aspects of biotechnology. These are: (1) don't dismiss lay hypotheses as ridiculous; (2) never ignore non-scientific points about biotechnology; and (3) never underestimate the intelligence or power of the public. Basically, the above principles spell out clearly that any hypotheses, fears, ignorances, etc. that arise must be explained as openly and clearly as possible. The public must understand that the communications they are receiving are "up front", honest, and as accurate as current knowledge allows. Nothing can be hidden or swept under the carpet, as this will only create long-term problems that may become unsolvable.

The introduction of transgenic baculoviruses as insect control agents have not met significant obstacles in the early stages of research and initial field releases in small plots, at least in the U.S. However, we can anticipate that once a full commercial registration is sought, issues will come forth from the public sector which could require additional safety and environmental testing. Even after the approval of commercial sales, there could be some resistance to the use of these products, based on ignorance, fear, or ethical reasons. This has clearly been the attitude of many European countries relative to transgenic crops. Although, recombinant baculoviruses have the advantage in not being incorporated into the crop. Your challenge will be to carry out this introduction and, meeting the informational needs to answer the societal issues of concern for each respective geographic unit (country, state, etc.). It can be expected that the concerns will be quite varied from country to country: This will be a major challenge for the OEDC to meet and solve in the years to come.

\section{THE FUTURE}

Genetically engineered baculoviruses, with insect-specific toxin genes inserted, will become a commercial reality within the next 2 - 3 years. These products will be limited to controlling only those hosts which are permissive to the infection of the wild-type baculovirus parents. This will remain a limiting factor for the widespread use of these baculoviruses. This limitation dictates the need to discover new baculoviral variants that have different hostranges (e.g., congruent with the crop pest spectrum). This will be accomplished through the careful observation and search in the field for baculoviruses infecting new target hosts. These baculovirus libraries will form the basis of genetic material from which to eventually draw and enable the generation of "designer baculoviruses" (second and third generation products) that will control insects in specific cropping scenarios. In the near future, researchers will discover the genetic basis for hostrange control of baculoviruses and will be able to mix-and-match the proper genes to meet the pest control requirements of many crop scenarios. It is envisioned that these designer baculoviruses could (at least initially) require some higher level of regulatory oversight. Finally, other viruses such as entomopox and granulosis viruses will emerge into the realm of transgenic baculovirus products. 


\section{SUMMARY}

In summary, we envision the role for OEDC members to help in educating the public and overcoming the societal issues connected with the commercialization and utilization of transgenic viruses for insect control. This activity is going to be essential to enable the widespread use of these recombinant products. This activity could require research to answer new public issues, as well as to add further support to the database answering older questions. Also, it will be important for OEDC research to concentrate on identifying new genetic material that will be usable in the development of other first generation baculoviruses (i.e., host-range limited to the wild-type parent) and in the future, for constructing second and third generation designer baculoviruses.

\section{REFERENCES}

American Cyanamid. 1994. Notification to Conduct Small-Scale Field Testing of a Genetically Altered Baculovirus. EPA No. 241-NMP-2. EPA-OPP Public Docket No. 50799.

Brown, Jr., G.E. 1987. Social and political aspects of risk assessment. In: Public Perceptions of Biotechnology. L.A. Batra and W. Klassen (Eds.). pp. 73-80. Agricultural Research Institute. Bethesda, MD.

Burges, H.D., Croizier, G., and Huger, J. 1980. A review of safety tests on baculoviruses. Entomophaga. 25:329-340.

Doller, G. 1985. The safety of insect viruses as biological control agents. In: Viral Insecticides for Biological Control, K. Maramorosch and K.E. Sherman (Eds.). pp. 399-439. Academic Press. New York.

Heimpel, A.M., and Buchanan, L.K. 1967. Human feeding tests using a nuclearpolyhedrosis virus of Heliothis zea. J. Invert. Pathol. 9:55-57.

Heimpel, A.M., Thomas, E.D., Adams, J.R., and Smith, L.J. 1973. The presence of nuclear polyhedrosis virus of Trichoplusia ni on cabbage from the market shelf. Environ. Entomol. 2:72-75.
Huang, H., Ignoffo, C.M., and Shapiro, M. 1977. Physical and clinical examinations of personnel involved in production of the insect virus, Baculovirus Heliothis. J. Kansas Entomol. Soc. 50:200-202.

Ignoffo, C.M. 1973. Effects of entomopathogens on vertebrates. Ann. NY Acad. Sci. 217:141-164.

Ignoffo, C.M. 1975. Entomopathogens as insecticides. Environ. Lett. 8:23-40.

Moskowitz, H., Hermann, R., Zlotkin, E., and Gordon, D. 1994. Variability among insect sodium channels revealed by selective neurotoxins. Insect Biochem. Mol. Biol. 24:13-19.

Wood, H.A. 1991. Development of Genetically Enhanced Baculovirus Pesticides. In: Biotechnology for Biological Control of Pests and Vectors. K. Maramorosch (Ed.). pp. 70-76. CRC Press. Boca Raton, FL, Ann Arbor, MI, Boston, MA, and London, UK.

Zlotkin, E., Eitan, M., Bindokas, M.E., Adams, M.E., Moyer, M., Burkart, W., and Fowler, E. 1991. Functional duality and structural uniqueness of depressant insect-selective neurotoxins. Biochemistry. 30:4814-4821.

Zlotkin, E., Gurevitz, M., Fowler, E., and Adams, M.E. 1993. Depressant insect selective neurotoxins from scorpion venom: Chemistry, action, and gene cloning. Arch. Insect Biochem. Physiol. 22:5573.

\section{QUESTIONS}

I. What cropping scenarios in OECD countries would benefit from a recombinant baculoviral insecticide? Why?

II. How will OECD countries address the regulatory issues for release of recombinant baculoviruses?

III. Will there be different issues (regulatory, ethical, etc.) to address in a release for testing vs. a release for commerce? 